\title{
In vitro Anti-Helicobacter pylori Activity of Capsaicin
}

\author{
Isra Tayseer ${ }^{1}(\mathbb{D})$, Talal Aburjai ${ }^{1}$ (D) , Luay Abu-Qatouseh² ${ }^{(\mathbb{D})}$, Nehaya AL- \\ Karabieh $^{3,4}$ (D) Wesam Ahmed $^{1,5}$ (i) and Ali Al-Samydai ${ }^{1 *}$ (D) \\ ${ }^{1}$ Department of Pharmaceutical Sciences, Faculty of Pharmacy, University of Jordan, Amman, Jordan. ${ }^{2}$ Faculty \\ of Pharmacy, Department of Biomedical Sciences, University of Petra, Amman, Jordan. ${ }^{3}$ Department of Plant \\ Protection, School of Agriculture, The University of Jordan, Amman, Jordan. ${ }^{4}$ Hamdi Mango Research Center \\ for Scientific Research, The University of Jordan, Amman, Jordan. ${ }^{5}$ College of Health and Life Sciences, Hamad \\ Bin Khalifa University, Education City, Qatar Foundation, Doha, Qatar.
}

\begin{abstract}
Worldwide, peptic ulcer and gastritis considered to be one of the biggest health challenge, Helicobacter pylori is responsible for more than eighty percent of chronic active gastritis where continual infection remains for decennary. However, the success of commercially available drugs for the management of $H$. pylori has overwhelmed by antibiotic-resistant strains, especially, metronidazole and clarithromycin, therefore, an urgent need arise to search for new options for treatment with enhanced anti- $H$. pylori activities, while being less toxic to human cells. Naturally occurring plant products, including spices, are one of these strategies that showed activity against $H$.pylori. Present study aim to test the antibacterial activity of capsaicin and other pure plant-derived compounds against a standard (NCTC 11916) H. pylori strain In vitro and to test for possible synergistic effect when combined with conventional therapy. Capsaicin shows good antibacterial activity on regular antimicrobial sensitivity testing methods (AntiMSTM) and titration checkerboard assay MIC $(0.0625 \mathrm{mg} / \mathrm{ml})$, whereas piperine MIC was $(0.125 \mathrm{mg} /$ $\mathrm{ml}$ ). While for curcumin no inhibition was found. The strain was found to be resistant to metronidazole with (MIC=250 $\mu \mathrm{g} / \mathrm{ml}$ ). When combining capsaicin with metronidazole, (FIC) Fractional inhibitory concentration values shown a synergistic effect, While the additive effect was found for capsaicin combination with piperine. Our obtained data indicate that capsaicin possesses promising anti H.pylori bioactivity and synergistic activity when combined with metronidazole but more work is necessary to examine the mechanisms by which these happened. Furthermore, it is necessary to ensure its activity against H.pylori In vivo and clinical settings.
\end{abstract}

Keywords: H. pylori, Capsaicin, Spices, Synergism

*Correspondence: PhAlimahmoud2012@yahoo.com; Tel.: +962788106069

(Received: March 01, 2020; accepted: March 21, 2020)

Citation: Isra Tayseer, Talal Aburjai, Luay Abu-Qatouseh, Nehaya AL-Karabieh, Wesam Ahmed and Ali Al-Samydai, In vitro AntiHelicobacter pylori Activity of Capsaicin, J. Pure Appl. Microbiol., 2020; 14(1):279-286. https://doi.org/10.22207/JPAM.14.1.29

(C) The Author(s) 2020. Open Access. This article is distributed under the terms of the Creative Commons Attribution 4.0 International License which permits unrestricted use, sharing, distribution, and reproduction in any medium, provided you give appropriate credit to the original author(s) and the source, provide a link to the Creative Commons license, and indicate if changes were made. 


\section{INTRODUCTION}

Helicobacter pylori is a type of gramnegative bacteria. $H$. pylori Infection occurs in more than 50 percent of the world's population (Tanih et al., 2008), which leads to develop chronic gastritis that could steps forward to be peptic ulcer disease, adenocarcinomas, (MALT) gastric mucosaassociated lymphoid tissue lymphoma, and other gastroduodenal diseases (Ernst and Gold, 2000). H. pylori was the first bacterium which classified as a class I carcinogen according to the WHO, (Peek and Blaser, 2003).

Various treating options designed for $H$. pylori infections; however, no single antibiotic can eradicate treatment so that, a combination of different antibiotics has been used. These antibiotics are often combined with Antisecretory agents such as proton pump inhibitors (PPIs) and/or histamine receptor ( $\mathrm{H} 2)$ antagonists (Gonzalez et al., 2014; McColl, 2010; Kusters et al., 2006; Nakayama and Graham, 2004).

However, the success of commercially available drugs for the management of $H$. pyloriassociated gastric disorders has overwhelmed by the various adverse effects associated with these drugs, noncompliance with patients, economical problem due to high price of the antibiotic regimens, in addition to the increase in antibioticresistant strains (especially to metronidazole and clarithromycin) (Graham, 2004; De, Kundu, 2009).

This leads to an insistent require to search for novel complementary and alternative treatment regimens with enhanced activity against H. pylori while being less toxic to human cells. One of these strategies is to go back to nature.

Traditionally Arabic communities including Jordanians used a lot of herbal preparations to treat minor complaints mainly gastrointestinal and respiratory-related problems (Abu-Irmaileh, and Afifi, 2003; Humam et al., 2020). Many of these herbs have a wide spectrum of antimicrobial and antifungal properties (Abu-Qatouseh et al., 2013). Previous in vitro and in vivo studies have shown support that plant products, such as spices, are effective against $H$. pylori (Toyoda, et al., 2015; O'Mahony et al., 2005). So it is time to go toward the use of natural sources against this bacterial infection and to find a strategy to prevent it. To do this, three compounds derived from commonly used spices in Jordan as daily food ingredients have been evaluated for their antimicrobial effectiveness against $H$. pylori in vitro, which are capsaicin, piperine, and curcumin.

Capsaicin, the chili peppers active ingredient, which represented more than $80 \%$ of extract, obtain from Capsicum plants (family Solanaceae) the most famous chili use wordwide (Sharma et al., 2013; Ali et al., 2019; Al-Samydai et al., 2019).

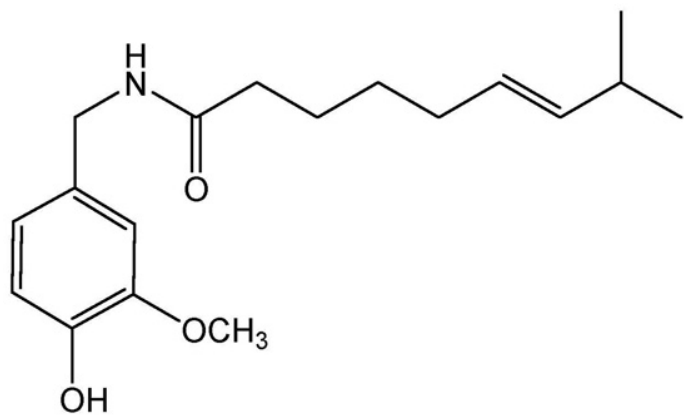

Fig. 1. The molecular structure of Capsaicin (Al-Samydai et al., 2019)

On the other hand, alkaloid Piperine, found in Black pepper (Piper nigrum) which is known as the "king of spices" (Tharmalingam, 2014) from the Piperaceae family. Finally, Curcumin is the principal constituent of turmeric which extracted from Curcuma longa rhizomes (family; Zingiberaceae) commonly used in food as spices and coloring agent (Mario et al., 2007; Mehmood et al., 2011).

This study aim to study the antimicrobial activity of Capsaicin (in vitro) on H. pylori standard strain, test the antimicrobial effect of capsaicin in combination with other spices against $H$. pylori strains and to study the possible synergetic effect of such combinations with conventionally used antibiotics to maximize the therapeutic effect or to reduce the side effects of them.

\section{MATERIALS AND METHODS}

All chemicals used in experments were HPLC grade. Dimethyl sulfoxide (DMSO) (Xilong chemicals, China), Capsaicin (Fluka, Switzerland) purchased from Sigma-Aldrich Chemicals, Piperine (Merck, Germany) and Curcumin (Sigma, USA).

\section{Bacterial Strain and Growth Conditions}

Columbia blood agar base (Oxoid, Hampshire, UK) was sterilized by autoclaving (121 ${ }^{\circ} \mathrm{C}$ for $15 \mathrm{~min}$ ) then enriched with laked horse 
blood in $7 \%$ (Oxoid, Hampshire, UK) and supplied with Helicobacter pylori selective supplement (Dent) (Oxoid, Hampshire, UK) (Mehmood et al., 2011). In this study, (NCTC 11916) standard strain of $H$. pylori was used and colonized to be used for testing.

Continuous subcultures of $H$. pylori were performed to increase the colony's yield and recovery. To achieve the needed microaerophilic conditions, plates were incubated in Candle jar 2.5L (Oxoid, Hampshire, UK) and $98 \%$ relative humidity at $37^{\circ} \mathrm{C}$. The suitable environment was achieved by using CampyGen Gas Pak (Oxoid, Hampshire, UK) and incubated for 7 Days 21. Selected colonies were picked with a sterile loop and transferred to Muller Hinton Broth media supplemented with fetal bovine serum $10 \%$ and glycerol $20 \%$ and then stored at $-80^{\circ} \mathrm{C}$ for subsequent tests and long term preservation (Abu-Qatouseh, 2016).

H. pylori growth, confirmed by characteristic of colony morphology, Gram staining, and conventional biochemical tests (positive for oxidase, catalase, and urease) (AbuSini, 2017).

\section{Anti-MSTM and MIC Determination}

Sterile blank (6 $\mathrm{mm}$ ) discs (Oxoid, Hampshire, UK) were soaked by $25 \mu \mathrm{L}$ of the tested compounds that which prepared in a concentration of $1 \mathrm{mg} / \mathrm{ml}$ dissolved in DMSO. Discs soaked with ciprofloxacin $1 \mathrm{mg} / \mathrm{ml}$ dissolve in DMSO had been used as a positive control, whereas DMSO soaked discs alone used as a negative control.

The freshly prepared bacterial suspension was prepared in sterile Phosphate Buffered Saline (PBS) to attuned turbidity to $6 \times 108$ CFU/ $\mathrm{ml}$ (2 McFarland) (Abu-Qatouseh, 2011) and consequently homogeneously spread on solid Columbia blood agar medium.

Discs placed on the surface of each agar plate and incubated for 5-7 days under suitable cultivation environment (Abu-Qatouseh, 2011). Experiments were performed in triplicates. MICs optained by two-fold agar dilution method (AbuQatouseh, 2011). Accordingly, all compound was in sequence diluted with DMSO and incorporated to agar plates with laked horse blood $7 \%(\mathrm{v} / \mathrm{v})$. On the surface of each plate, spots of $H$. pylori suspension (6x 108CFU) were applied. After 7 days, visible colonies growth $\left(37^{\circ} \mathrm{C}\right.$ under microaerophilic conditions) was determined. The
MIC was triplicate measured.

\section{In-vitro Interaction Determination}

Interaction between capsaicin and metronidazole In vitro, and between capsaicin and piperine against a standard $\mathrm{H}$. pylori, was optained by Checkerboard test (Abu-Sini et al., 2017; Odds, 2003). Tested compounds were dissolved in serially diluted with DMSO then homogenized mixed with molten Columbia blood agar media triplicatly.

FICs were calculated as follows:

$$
F I C=\left(\frac{\text { MIC of dung A in combination }}{\text { MIC of ding A alone }}+\frac{\text { MIC of dug B inc combination }}{\text { MIC of dung B a lone }}\right)
$$

The FIC index, interpreted as follows: $\leq 0.5$, synergy; 0.5-1, additive; $1-4.0$, indifference; $>4.0$, antagonism (Abu-Sini et al., 2017; Odds, 2003).

\section{Urease Inhibition Assay}

Quantitative determination of urease inhibition was performed using the standard colorimetric method (Abu-Sini et al., 2017). In brief, $10 \mu \mathrm{l}$ of $H$. pylori suspension in PBS (adjusted to an absorbance of 1.5 at a wavelength of $600 \mathrm{~nm}$ ) were mixed with an equivalent quantity of serially diluted solution of capsaicin in 96 well plates upto 30 minutes at $37^{\circ} \mathrm{C}$. $200 \mu \mathrm{l}$ of detecting reagent composed of $50 \mathrm{mM} \mathrm{PB} \mathrm{(pH} \mathrm{6.8)} \mathrm{of} \mathrm{urea} \mathrm{(500} \mathrm{mM)}$ and phenol red (0.02\%) (Oxoid,CM0053, UK) add to each well. The develop color was monitored at $555 \mathrm{~nm}$ measuring OD in a 5-minute interval for 2 hrs. bacteria with DMSO and bacteria with PBS as Negative controls. Other controls included capsaicin alone without bacteria. PBS and DMSO were used as blanks.

The percentage of inhibition was calculated by the equation;

Percentage of Inhibition = [ (activity without capsaicin - activity with capsaicin) / activity without capsaicin ] $\times 100$

Compartion was done with a urease inhibitor; $3 \mathrm{mg} / \mathrm{ml}$ Acetohydroxamic acid (AHA) as reference [Sigma, USA].

\section{RESULTS AND DISCUSSION}

Antimicrobial Activity against MetronidazoleResistant $\boldsymbol{H}$. pylori

Our preliminary screening showed that capsaicin and piperine possess considerable antibacterial activities against $H$. pylori in 
comparison to ciprofloxacin. Similar antibacterial activities of the above compounds were previously reported (Zeyrek and Oguz, 2005; Jones et al., 1997; Lee et al., 2007). On the other hand, curcumin did not show any effect against $H$. pylori as reported previously by other researchers (Sarkar and Mukhopadhyay, 2016). This controversy could be explained by different factors including variations in strains used and their susceptibility or resistance to antimicrobial agents, in addition to the methodology applied in this study.

Capsaicin and piperine showed strong inhibition effect against $H$. pylori with an average zone of inhibition of $15 \mathrm{~mm}$ and $12 \mathrm{~mm}$, respectively. The tested $H$. pylori strain is considered sensitive for both capsaicin and piperine with zones of inhibition exceed $11 \mathrm{~mm}$ (Adeniyi, 2012) obtained results shown agreement with a study done by Zeyreket al., 2005, which concluded that capsaicin began to inhibit both metronidazole resistant and metronidazole sensitive $H$. pylori clinical isolates at the minimum concentration $25 \mu \mathrm{g} / \mathrm{ml}$. The mechanism by which this is happening is still unknown. Thus, it might be recommended to take small amounts of hot pepper for patients with gastric or duodenal ulcers since heavy ingestion of high doses of the compound has been associated with necrosis, ulceration and even carcinogenesis (Surh and Lee, 1996; Rollyson, 2014). Toyoda et al., 2015 demonstrated that capsaicin shown anti-inflammatory activity against $H$. pylori- by inhibition of inflammatory factors such as Tnf- $\alpha$.

Taken together, these findings suggest that capsaicin or chili peppers hold a promise in the treatment and prevention of $H$. pylori linked diseases, which might be related to the inhibition of growth and colonization of $H$. pylori resistant strains of and for patients which preferred natural products rather than synthetic antibiotics. It was also demonstrated the piperine inhibition activity against $H$. pylori growth and found that it inhibits growth completely at a concentration of $0.125 \mathrm{mg} /$ $\mathrm{ml}$ as shown in our MIC findings.

Tharmalingam et al. 2014 investigated the inhibitory action of piperine on $H$. pylori growth and adhesion. Their study showed that piperine has suppressed the level of $H$. pylori adhesion to gastric adenocarcinoma cells in a dose-dependent manner by suppressing the flagellar hook gene $f l g E$ and integral membrane component of the export apparatus gene flhA expression. Suppression of both genes leads to less motility which results in less attacking of $H$. pylori to the gastric epithelial cells which might be the possible reason in the adhesion inhibition.

Besides, piperine suppressed expression of many inflammatory factors $/ 1-16$, Tnf- $\alpha$ and II-6, and the infiltration of neutrophils and mononuclear cells have been also suppressed both in the antrum and corpus of $H$. pylori-infected gerbils when treated with 100 ppm piperine Toyoda, 2015.

Our results propose that piperine could have potential as an alternative agent for the eradication of $H$. pylori infection and preventing chronic gastritis linked with it. Present findings recommend that combination of capsaicin and piperine could be used as part of the regimen for the management of $H$. pylori.

In vitro interactions between capsaicin and piperine and between capsaicin and metronidazole

It has been reported that the high rate of metronidazole resistant $H$. pylori is increasingly reported in Jordan due to the misuse of metronidazole (the frequently prescribed drugs by the general practitioners for the treatment of protozoal infections and gynecological problems) (Abu-Qatouseh et al., 2016). Based on these findings it is worthy to study the synergistic effects between metronidazole and capsaicin.

To the best of our knowledge, there are no reports about the use of capsaicin and metronidazole for their synergistic effect against H. pylori.

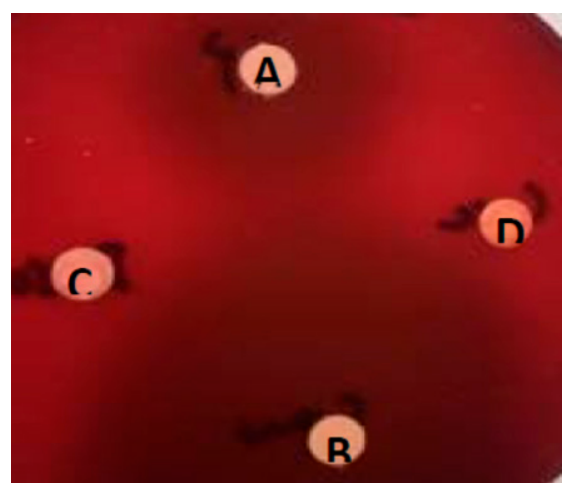

Fig. 2. Antimicrobial susceptibility tests (disc diffusion) of $1 \mathrm{mg} / \mathrm{ml}$ of A: capsaicin, B: ciprofloxacin, C: DMSO and D: curcumin against $H$. pylori strain. 
The combination showed that MIC for metronidazole decreased by eight -folds when combined with capsaicin. The MIC for capsaicin was $62.5 \mu \mathrm{g} / \mathrm{ml}$ and the MIC for capsaicin in combination was $15.625 \mu \mathrm{g} / \mathrm{ml}$. The MIC for metronidazole was $250 \mu \mathrm{g} / \mathrm{ml}$ and the MIC for metronidazole in combination was $31.25 \mu \mathrm{g} / \mathrm{ml}$. Metronidazole and capsaicin FIC value means were 0.126 and 0.25 respectively, FIC index for their combination was 0.376 which indicated that this combination was synergic. Capsaicin has potential synergy with antibiotic metronidazole and thus suggested that higher eradication success rates with this antibacterial combination using lower doses of metronidazole, thus minimizing toxicity and the chance for resistance issues and thus lowering the cost of treatment.

However, in our studies, the mechanism of this synergistic activity was not investigated. Although it might affect one of the metronidazole resistance mechanisms, that are caused by the failure of enzymatic reduction and prevented the production of antibacterial metabolites. This resistance mechanism has been elucidated with mutations of genes encoding certain electron transport proteins operative in the reduction process $r d x A$ and $f r x A$. Other mechanisms have been suggested as the cause of metronidazole

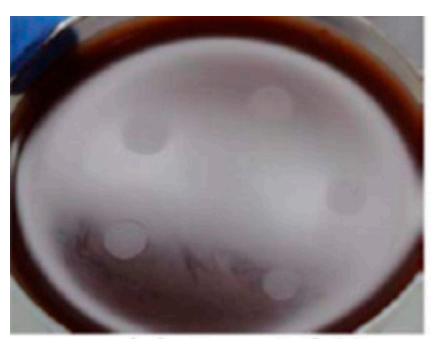

capsaicin $1 \mathrm{mg} / \mathrm{ml}(-)$

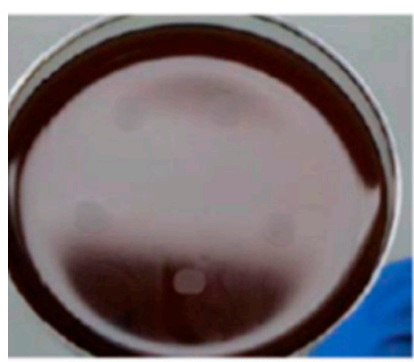

capsaicin $0.125 \mathrm{mg} / \mathrm{ml}(-)$

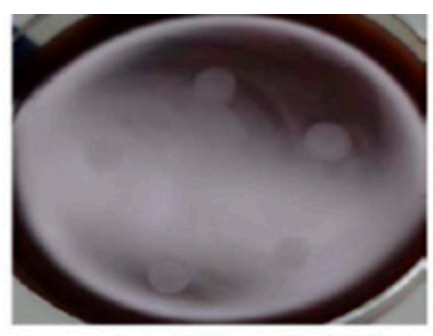

capsaicin $0.5 \mathrm{mg} / \mathrm{ml} \mathrm{(-)}$

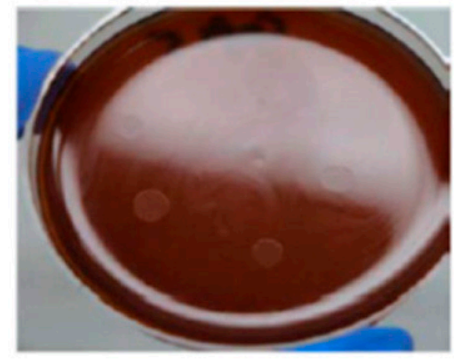

capsaicin $0.0625 \mathrm{mg} / \mathrm{ml} \mathrm{(-)}$

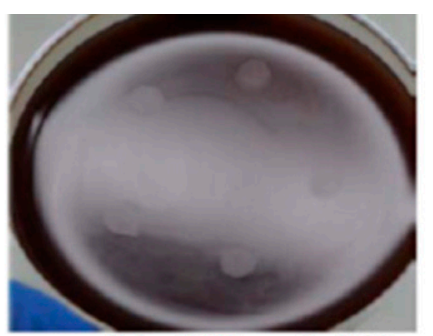

capsaicin $0.25 \mathrm{mg} / \mathrm{ml}(-)$

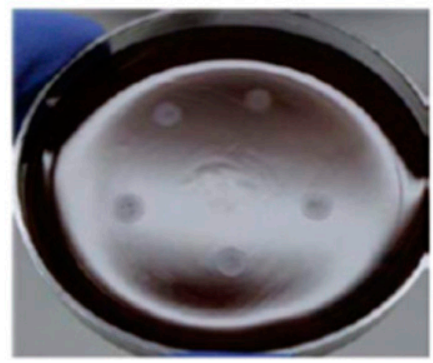

capsaicin $0.03125 \mathrm{mg} / \mathrm{ml}(+)$

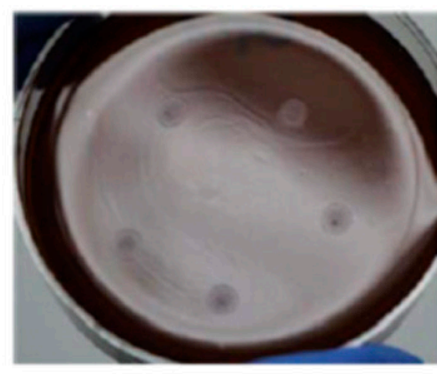

capsaicin $0.015625 \mathrm{mg} / \mathrm{ml}(+)$

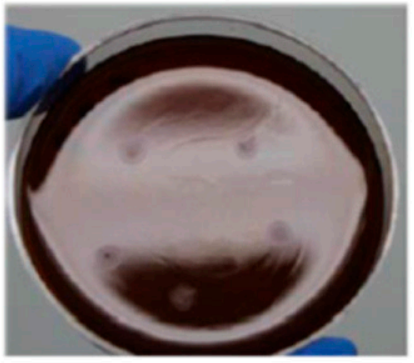

capsaicin $0.0078125 \mathrm{mg} / \mathrm{ml} \mathrm{(+)}$

Fig. 3. Minimum inhibitory concentration $(\mathrm{mg} / \mathrm{ml})$ of capsaicin against reference strain 
resistance in $H$. pylori such as involvement of efflux pump gene hefA 31 Since it was reported that capsaicin has reduced the MIC of ciprofloxacin by inhibiting the NorA efflux pump, thus reducing the intracellular invasion of Staphylococcus aureus. Whereas, capsaicin combination with piperine showed additive effect where MIC for capsaicin was $62.5 \mu \mathrm{g} / \mathrm{ml}$ and the MIC for capsaicin combination with metronidazole was $15.625 \mu \mathrm{g} / \mathrm{ml}$ as shown in figure 4.

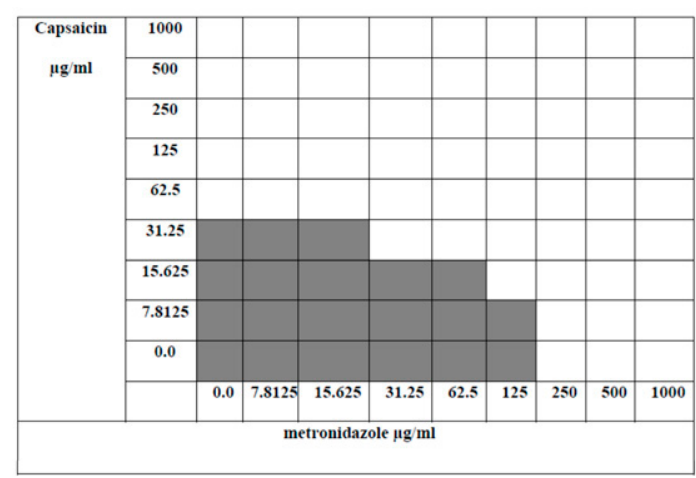

Fig. 4. Checkerboard method showing the prepared diluted concentrations of capsaicin and metronidazole (bolded squares refers to a positive bacterial growth)

While for piperine MIC was $125 \mu \mathrm{g} / \mathrm{ml}$ and the MIC for piperine in combination was $31.25 \mu \mathrm{g} / \mathrm{ml}$ as shown in figure 5 . FIC value means of capsaicin and piperine were 0.5 and 0.25 respectively, and the FIC index for the combination was $(0.75)$ which indicated that this combination has an additive effect.

Although the additive antibacterial effect was reported for such combinations, this combination may have a potential effect when it goes to in vivo interaction where piperine might improve the bioavailability of capsaicin and hence improve its activity and lead to the use of lower doses of capsaicin while maintaining its antibacterial activity.

Inhibitory Effect Capsaicin against H. pylori Urease Enzyme

Several studies have suggested a role for H. pylori urease in the survival and pathogenesis of the $H$. pylori. In this study, evaluation of the urease inhibitory potential of capsaicin was achieved by using the colorimetric method to determine the percent inhibitory activity of capsaicin over a concentration range of 31.25$1000 \mu \mathrm{g} / \mathrm{ml}$. Compounds achieving less than $60 \%$ inhibition are considered to have no significant effect Abu-Qatouseh et al., 2013. Capsaicin showed insignificant inhibitory activity $(<15 \%$ inhibition) over the tested concentration range. The previous study by Modolo et al., 2015 showed that inhibiting urease activity by capsaicin was achieved at concentrations reaching $10 \mathrm{mg} / \mathrm{ml}$.

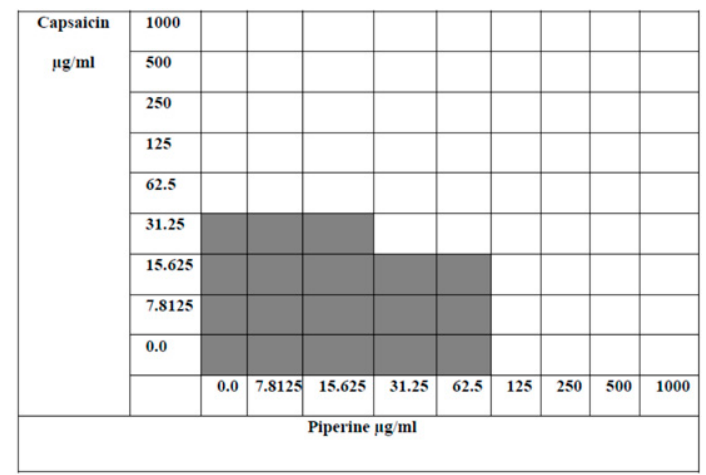

Fig. 5. Checkerboard method showing the prepared diluted concentrations of capsaicin and piperine (bolded squares refers to a positive bacterial growth)

\section{CONCLUSIONS}

The antibacterial activity of capsaicin and piperine against $H$. pylori was confirmed and thus could be considered for added values of the treatment of $H$. pylori particularly if the in vivo studies proved this concept. Our obtained data indicate that they possess promising anti- $H$. pylori bioactivity but more work is necessary to examine the inhibitory mechanism of capsaicin and piperine against $H$. pylori. Furthermore, it is necessary to ensure their activity against $H$. pyloriin vivo and on clinical settings taking into consideration the possibility of synergistic effect of capsaicin when combined with metronidazole, so that it might be used as dietary supplements to complement and expedite current treatment regimens although more future work is needed to determine the factors that could affect the efficacy of capsaicin including dosage forms, presence of delivery system, addition of anti-acids, etc. and the synergistic mechanism by which it improves the activity of metronidazole. 


\section{ACKNOWLEDGMENTS}

None.

\section{CONFLICT OF INTEREST}

The authors declare that there is no conflict of interest.

\section{AUTHORS' CONTRIBUTION}

All authors listed have made a substantial, direct, and intellectual contribution to the work, and approved it for publication.

\section{FUNDING}

This work was supported by Deanship of Scientific Research, University of Jordan, Amman, Jordan, for the fulfillment of the requirements for the master degree.

\section{DATA AVAILABILITY}

All datasets analyzed in the study are included in the manuscript and presented as tables and figures.

\section{ETHICS STATEMENT}

Not applicable.

\section{REFERENCES}

1. Abu-Irmaileh, B. E. and Afifi, F. U. Herbal medicine in Jordan with special emphasis on commonly used herbs. J.Ethnopharmacol., 2003, 89, 193-197. https://doi.org/10.1016/S0378-8741(03)00283-6

2. Abu-Qatouseh, L., Boutennoune, H., Boussouf, L., Madani, K., Shihab, P. and Al-Qaoud, K. In vitro susceptibility of Helicobacter pylori to urease inhibitory effects of polyphenolic extracts of local herbs from Algeria. The International Arabic Journal of Antimicrobial Agents. 2013, 3 (4), 4-13.

3. Abu-Qatouseh, L., Darwish, R., Abu-Sini, M., Mayyas, A., Abdo, Q., Sabri, I. and Aburjai, T. Molecular characterization and antibiotic susceptibility profiles of Helicobacter pylori isolated from patients with gastroduodenal diseases in Jordan. The International Arabic Journal of Antimicrobial Agents. 2016, 6(3), 4-14. https://doi.org/10.3823/794

4. Abu-Sini, M., Mayyas, A., Al-Karablieh, N., Darwish, R., Al-Hiari, Y., Aburjai, T., Arabiyat, S., Abu-Qatouseh, L. Synthesis of 1,2,3-triazolo[4,5-h]quinolone derivatives with novel anti-microbial properties against metronidazole resistant Helicobacter pylori. Molecules. 2017, 22(5), 841-853. https://doi. org/10.3390/molecules22050841

5. Adeniyi, B., Lawal, T., Otegbayo, J., Oluwasola, O., Odaibo, G., Ola, S., Okolo, C., Akere, A. and Kehinde, A. Cultural characteristics and antibiotic susceptibility pattern of Helicobacter pylori isolated from dyspepsia patients. Gastroenterol. Insights., 2012, 4, 87-89. https://doi.org/10.4081/gi.2012.e21

6. Ali Al-Samydai, Talal Aburjai, Walhan Alshaer, Hanan Azzam, and Farah Al-Mamoori. "Qualitative and Quantitative Analysis of Capsaicin from Capsicum Annum Grown in Jordan". International Journal of Research in Pharmaceutical Sciences, 2019; 10(4), 3768-74. https://doi.org/10.26452/ijrps.v10i4.1767

7. Al-Samydai, Ali, Farah Al- Al-Mamoori, Hiba Abdelnabi, and Talal Aburjai ."An Updated Review on Anticancer Activity of Capsaicin." International Journal of Scientific \& Technology Research, 2019; 8(12): 2625-2631.

8. De, R., Kundu, P., Swarnakar, S., Ramamurthy, T., Chowdhury, A., Balakrish, G. and Mukhopadhyay, A. Antimicrobial activity of curcumin against Helicobacter pylori isolates from india and during infections in mice. Antimicrob. Agents Chemother., 2009, 53, 1592-1597. https://doi.org/10.1128/ AAC.01242-08

9. Ernst,P.B., and Gold,B.D. The disease spectrum of Helicobacter pylori:theimmunopathogenesis of gastro duodenal ulcer and gastric cancer. Annu. Rev. Microbiol., 2000, 54, 615-640. https://doi. org/10.1146/annurev.micro.54.1.615

10. Gonzalez, E.G., Perez-Perez, G. I., MaldonadoGarza, J. H. and Padilla, F. J A review of Helicobacter pylori diagnosis, treatment, and methods to detect eradication. World J. Gastroenterol., 2014, 20(6): 1438-1449.

11. Humam M. Al-Somaiday, Manar E. Al-Samaray, and Ali Al-Samydai. "Role of Herbal Medicine in Oral and Dental Health; Ethnopharmacological Study of Medicinal Plants in Iraq/Baghdad". International Journal of Research in Pharmaceutical Sciences, 2020; 11(1), 553-60. https://doi.org/10.26452/ijrps. v11i1.1857

12. Jones, N.L., Shabib, S. and Sherman, P.M. Capsaicin as an inhibitor of the growth of the gastric pathogen Helicobacter pylori. FEMS Microbiol. Lett., 1997, 146(2), 223-227. https://doi. org/10.1111/j.1574-6968.1997.tb10197.x

13. Kusters,J.G., Vliet,A.H., and Kuipers,E.J. Pathogenesis of Helicobacter pylori infection. Clin. Microbiol. Revi., 2006, 19(3), 449-490. https://doi.org/10.1128/ CMR.00054-05

14. Lee, I.O., Lee, K.H., Pyo, J.H., Kim, J.H., Choi, Y.J. and Lee, Y.C. Anti-inflammatory effect of capsaicin in Helicobacter pylori-infected gastric epithelial cells. Helicobacter. 2007, 12, 510-517. https://doi. org/10.1111/j.1523-5378.2007.00521.x

15. Mario, F., Cavallaro, L., Nouvenne, A., Stefani, N., Cavestro, G., Iori, V., Maino, M., Comparato, G., Fanigliulo, L., Morana, E., Pilotto, A., Martelli, L., Martelli, M., Leandro, G. and Franzè, A. A curcuminbased 1-week triple therapy for eradication of Helicobacter pylori infection: something to learn from failure?. Helicobacter. 2007, 12, 238-243. https:// doi.org/10.1111/j.1523-5378.2007.00497.x

16. McColl, K. E. Helicobacter pylori Infection. $N$ Engl J Med., 2010, 362(17), 1597-1604. https://doi. 
org/10.1056/NEJMcp1001110

17. Mehmood, K., Shoukat, S., Hameed, Z., Hussain, M., Ahmed, S., Shah, A. A., Hameed, A. and Hasan, F. Evaluation of various strategies for isolation and culturing of Helicobacter pylori. Pak. J. Zool., 2011, 43(3), 427- 435.

18. Min, S., Kim, N., Kwon, Y., Hee, R., Kim, J., Youn, J., Lee, Y. and Lee, D. rdxA, frxA and efflux pump in metronidazole-resistant Helicobacter pylori: their relation to clinical outcomes. J.Gastroenterol. Hepatol., in press.2018,33(3), 681-688. https://doi. org/10.1111/jgh.13906

19. Modolo, L. V., de Souza, A. X., Horta, L. P., Araujo, D. P., \& de Fatima, A. An overview on the potential of natural products as ureases inhibitors: A review. J. Adv. Res., 2015, 6(1), 35-44. https://doi. org/10.1016/j.jare.2014.09.001

20. Nakayama, Y. and Graham, D. Y. Helicobacter pylori infection: diagnosis and treatment. Expert Rev. Anti Infect. Ther., 2004, 2(4), 599-610. https://doi. org/10.1586/14787210.2.4.599

21. O'Mahony, R., Al-Khtheeri, H., Weerasekera, D., Fernando, N., Vaira, D., Holton, J. and Basset, C. Bactericidal and anti-adhesive properties of culinary and medicinal plants against Helicobacter pylori. World J. Gastroenterol., 2005, 11(47), 7499- 7507. https://doi.org/10.3748/wjg.v11.i47.7499

22. Odds, F. C. Synergy, antagonism, and what the chequerboard puts between them. J. Antimicrob. Chemother., 2003, 52, 1-1. https://doi.org/10.1093/ jac/dkg301

23. Peek, R. J. and Blaser, M. J. Helicobacter pylori and gastrointestinal tract adenocarcinomas. Nat.Rev. Cancer., 2002, 2, 28-37. https://doi.org/10.1038/ nrc703

24. Rollyson, W.D., Stover, C.A., Brown, K.C., Perry, H.E., Stevenson, C.D., McNees, C.A., Ball, J.G., Valentovic,
M.A. and Dasgupta, P. Bioavailability of capsaicin and its implications for drug delivery. J. Control. Release., 2014, 0, 96-105. https://doi.org/10.1016/j. jconrel.2014.09.027

25. Sarkar, A., De, R. and Mukhopadhyay, A. Curcumin as a potential therapeutic candidate for Helicobacter pylori associated diseases. World J. Gastroenterol., 2016, 22(9): 2736-2748. https://doi.org/10.3748/ wjg.v22.i9.2736

26. Sharma, S. K., Vij, A.S. and Sharma, M. Mechanisms and clinical uses of capsaicin. Eur. J. Pharmacol., 2013, 720, 55-62. https://doi.org/10.1016/j. ejphar.2013.10.053

27. Surh, Y.J. and Lee, S.S. Capsaicin in hot chili pepper: carcinogen, co-carcinogen or anticarcinogen. Food Chem.Toxicol., 1996, 34(3), 313-316. https://doi. org/10.1016/0278-6915(95)00108-5

28. Tanih,N.F.,Clarke,A.M.,Mkwetshana, N., Green, E., Ndip, L.M. and Ndip, R.N. Helicobacter pylori infection in Africa: Pathology and microbiologicaldiagnosis. Afr. J. Biotechnol., 2008, 7, 4653-4662.

29. Tharmalingam, N., Kim, S., Park, M., Woo, H., Kim, H., Yang, J., Rhee, K. and Kim, J. Inhibitory effect of piperine on Helicobacter pylori growth and adhesion to gastric adenocarcinoma cells. Infect. AgentsCancer., 2014, 9, 43-53. https://doi. org/10.1186/1750-9378-9-43

30. Toyoda, T., Shi, L., Takas, S., Cho, Y. M., Kiriyama, Y., Nishikawa, A., Ogawa, K., Tatematsu, M. and Tsukamoto, T. Anti-inflammatory effects of capsaicin and piperine on Helicobacter pylori-induced chronic gastritis in mongolian gerbils. Helicobacter. 2015, 21, 131-142. https://doi.org/10.1111/hel.12243

31. Zeyrek, F.Y. and Oguz, E. In vitro activity of capsaicin against Helicobacter pylori. Ann. Microbiol., 2005, 55(2), 125-127. 